\title{
MENTAL MODELS AS ENABLERS OF KNOWLEDGE SHARING AND DECISION-MAKING IN THE DESIGN OFCOLLABORATIVE NETWORKED ENVIRONMENTS
}

\author{
Ure J, Dewar R, Pooley R, Lloyd A and Jaegersberg J \\ University. of Edinburgh, Jenny.Ure@ed.ac.uk; Ashley@ed.ac.uk \\ Heriot Watt University, rgd@macs.ac.uk; rip@macs.ac.uk \\ Zwickau University, Gudrun.Jaegersberg@mailbox-dresden.tu
}

\begin{abstract}
This article draws initial conclusions from multiple cases of knowledge sharing in the collaborative design of networked systems. The studies look at the different ways in which different project teams have created and/or used shared mental models tofacilitate the collective representation, configuration or re-use of knowledge. It draws analogies with other 'interface languages' for knowledge representation and across social, technical and organizational domains. It has implications for the role of shared mental models in knowledge sharing and decision support in the design ofnetworked systems, where these require trade-offs between technical constraints on the one hand, and the social, organisational and professional requirements of stake-holding communities on the other.
\end{abstract}

\section{INTRODUCTION}

The design of virtual environments is itself testament to the role of mental models in mediating shaping our perceptions and our actions. Ben Shneiderman's 'Codex, Memex, Genex' paper in 1998, traces the changes in the models and metaphors that have informed our changing approach to the design and use of networked systems since Vannevar Bush first anticipated them in Atlantic Monthly in 1945. Our models of networked systems have evolved from passive repositories of information to a medium for leveraging the human and the technical resource to recreate and restructure distributed knowledge. Central to that change is a shared model of how distributed knowledge can be collectively situated, aligned and restructured to advantage. 


\subsection{The Social Construction of Technical Systems}

Knowledge representation, construction and use are increasingly perceived as socially constructed and situated (Tyre et al, 1997). This process may be naturally scaffolded in social contexts, but may have to be explicitly created for distributed teams (Prusak, 1997; Wenger 1998; Nonaka, 1998;and Von Krogh and Roos, 1950. Three strands are suggested in the literature:

\section{1. shared spaces in which distributed teams can interact}

2. shared frames of reference such as models, metaphors or problem scenarios through which to derive meaning and in which to contextualise decision-making

3. processes whereby social capital and intellectual capital can generate organizational value through the work of real and virtual project teams

System design is a high cost, high-risk undertaking (Adams, 2001) requiring effective collaboration and knowledge sharing across very diverse and often geographically distributed communities, with different aims and criteria for success. As the scale and scope of systems in the extended enterprise has grown, the difficulties of 'sense-making' across interdependent communities have become more critical, and the interdependence of social and technical knowledge has become more apparent (Lloyd et al, 2002; Bijker, 1989).

This paper looks at how project design teams organised distributed knowledge of system design. The examples are based on the use of design 'patterns' as the lingua franca (Alexander, 1964; Coplien 1995). Cases or scenarios could equally have been used as the basic unit of currency. These can be related in different ways and for different purposes. The way that shared frames of reference are created or adopted and 'shape' this process is the focus of this initial exploration.

The basic unit of currency used by the project was patterns, which are typically connected as a pattern 'languages' in that they represent in many cases transactions between agents in particular contexts. This is used to make requirements in the real world accessible to technical developers, or re-usable (Gamma et al, 1995). A number of 'languages' or 'interface languages' such as UML or 'Unified Mark-up Language' (Pooley \& Stevens, 1999) have become the 'de facto' standard, as a means of interfacing the transactions in the real world and technical and the social/business architecture of such systems.

\subsection{Situating distributed knowledge}

We draw on a range of industry-based examples to highlight the nature of the process as it was observed in research on socio-technical pattern building in system design. While the companies involved were concerned with use of patterns to encapsulate and potentially re-use volatile or tacit knowledge of solutions to recurring problems, we make observations on characteristics of the process of developing a shared conceptual, social, and organisational space that was observed, and on the observation by both researchers and participants that the process itself was more important than the patterns which were the product. Alexandrian patterns and cases use 'the problem' as a common frame of reference around which diverse groups can structure their input. By situating this in a real world context, or one cocreated by the group, this can mitigate the lack of shared context. 
Both the recorded conversations and the connected patterns (pattern language) indicated that participants organised information or knowledge (e.g. patterns) around a shared scenario. This may be the problem scenario itself, a shared 'metaphor' or familiar process such as the project timeline, or for example the organisation itself, as the locus of situated action. This provided the scaffolding around which distributed knowledge could be drawn together as the basis for collective understanding and decision-making.

We present situated examples where semantic 'units' were connected in different ways, suggesting shared models had been adopted or created to 'enable' both the 'sense-making'. We explore the hypothesis that 'situating' (Suchman, 1987) distributed knowledge shapes the sense-making and the decision-making processes, and whether this is enlightening or constraining, requires the creation of such opportunities in distributed and heterogeneous environments.

\subsection{Methodology}

The method of data collection was collaborative action research, (Denzin, 1994) to support the co-creation of collectively represented 'patterns' through elicitation from interview, and an iterative process of validation, refinement and peer review involving both actors and researchers.

\section{CASE STUDY RESULTS}

The main company under consideration in this study cannot be named for reasons of commercial confidentiality, however it is one of the UK's largest life assurance, investment and pensions companies. In addition, companies in the oil and gas, software and automotive manufacturing sectors were also involved in validating some of the recurring problem: solution scenarios in the design and management of extended enterprise systems.

\subsection{Shared mental model 1: the time-line}

In the following example we present the simplest enabling frame - the chronological time frame. Figure 1 shows what is commonly referred to in the patterns community as a 'roadmap' as pattern communities term it. Here, the arcs represent links between related patterns that have potential for synergistic use. We have superimposed a timeline on the roadmap in an attempt to demonstrate the loose grouping during (a) a project's start-up phase (where feasibility was established) and (b) during implementation (where cost and time became more critical). 


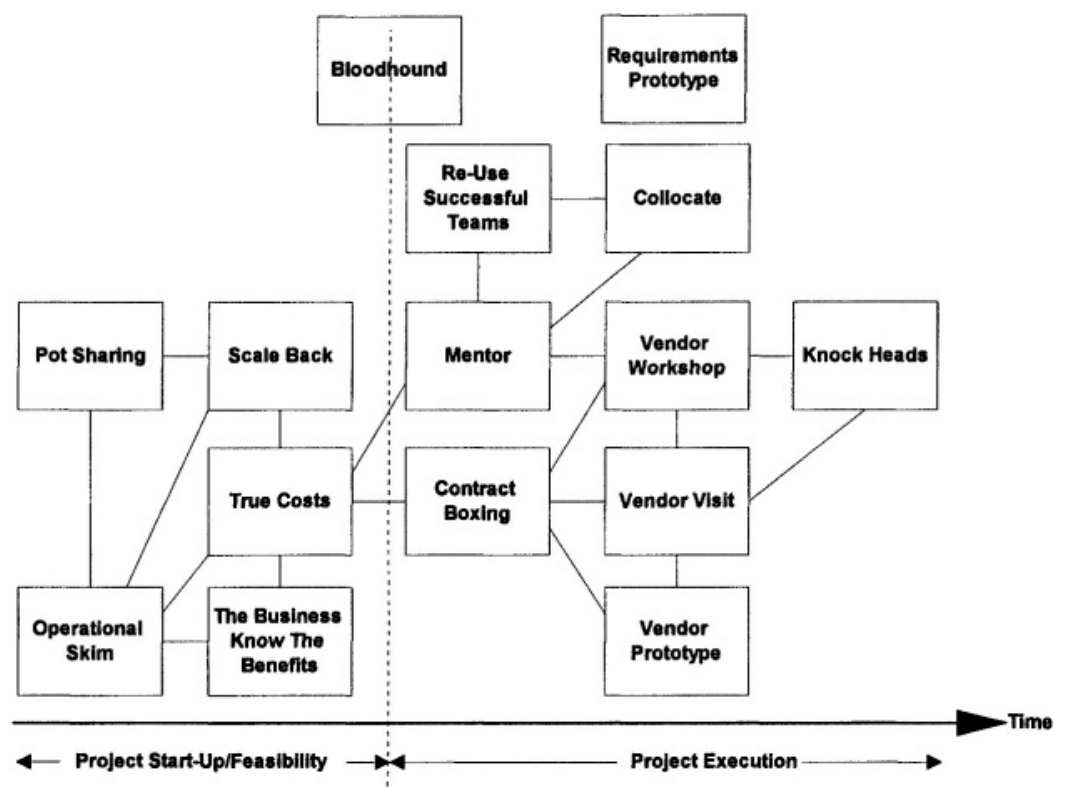

Figure 1. Project Management Patterns

The patterns make sense when situated in a temporal context. Timing and cost were key criteria for success for this group. These were typically the criteria for success used by technical project managers, and structured both their understanding and their decision-making preferences.

Those on the left are primarily concerned with finding the money to finance the proposal and trying to establish what benefits would be realised. The patterns in the execution phase looked at team building and vendor management. In this case, both the lingua franca and the frame of reference were shaped by unifying need to map and manage distributed knowledge as a means of cutting project development time.

The temporal linkages reflect the concern of the team with the 'knock on' effects of unresolved problems (social, organizational and technical) in the initial start up/feasibility stage, and subsequently in the project execution phase later on. The sequence of events and the use of a timeline echoed the concern with the team with the acknowledged problem of overrun and delay in previous project work.

The problems could therefore be most meaningfully organised in relation to the time-line as the project unfolded. This implicit context was a shared frame of reference for the team in this case. Time and space are dimensions we all share, and thus provide ready made templates for scaffolding collective knowledge in intuitively meaningful ways. Other templates appear to need to be developed by the group through dialogue.

\subsection{Shared mental model 2: the problem}

The example presented in Table 5 shows the conceptual relationship of various solutions to a core problem in system design (over-capacity). Cranmore et al (2002). 
Table1

\begin{tabular}{|c|c|c|c|}
\hline Context & Problem & $\begin{array}{l}\text { Competing } \\
\text { Requirements }\end{array}$ & Solutions \\
\hline \multirow{5}{*}{$\begin{array}{l}\text { Volatility of a } \\
\text { more } \\
\text { distributed and } \\
\text { increasingly } \\
\text { user-led market } \\
\text { in the extended } \\
\text { enterprise } \\
\text { makes resource } \\
\text { planning and } \\
\text { management } \\
\text { difficult to } \\
\text { forecast and } \\
\text { manage } \\
\text { effectively. }\end{array}$} & \multirow{5}{*}{$\begin{array}{l}\text { How can } \\
\text { business respond } \\
\text { rapidly \& } \\
\text { effectively to } \\
\text { transient user } \\
\text { requirements } \\
\text { without costs \& } \\
\text { risks inherent in } \\
\text { Over or Under- } \\
\text { build? } \\
\text { Over capacity is } \\
\text { costly and } \\
\text { invokes other } \\
\text { costs/risks such } \\
\text { as security } \\
\text { Under capacity } \\
\text { can lead to loss } \\
\text { of business due } \\
\text { to poor service } \\
\text { or system failure }\end{array}$} & \multirow{5}{*}{$\begin{array}{l}\text { Maximize } \\
\text { response to } \\
\text { changing scale } \\
\text { and scope of } \\
\text { user } \\
\text { requirements } \\
\text { Minimize cost } \\
\text { of system } \\
\text { build and/or } \\
\text { redesign } \\
\text { Maintain } \\
\text { reliability, } \\
\text { security, } \\
\text { flexibility of } \\
\text { service }\end{array}$} & $\begin{array}{l}\text { 1a.Share } \\
\text { Resources }\end{array}$ \\
\hline & & & $\begin{array}{l}\text { 1b.Share } \\
\text { Resources } \\
\text { Dynamically }\end{array}$ \\
\hline & & & $\begin{array}{l}\text { 1c.Target } \\
\text { Resources }\end{array}$ \\
\hline & & & $\begin{array}{l}\text { 1d.Outsource } \\
\text { Transient } \\
\text { Capacity }\end{array}$ \\
\hline & & & $\begin{array}{l}\text { le.Align } \\
\text { Short-Term } \\
\text { Build with } \\
\text { Long-Tem } \\
\text { Planning }\end{array}$ \\
\hline
\end{tabular}

This set of patterns, reduced here to one table, is taken from the context of ebusiness, and, like case based reasoning, (Aamodt, 1997) it provides a range of solutions to a generic problem. In the comparable case of 'rich pictures' in Soft Systems Methodology (Checkland, 1981), the situation of this in the problem scenario roots it in a shared context of real operations in specific contexts within the organisation where a great deal of tacit knowledge and understanding can be tapped.

The comparison of different options in a rich context appears able to support informed dialogue about the nature of the similarities and differences, and creative reflection on the way the forces can best be configured to resolve the problem. (Kolodner, 1997; Ross, 1990). The awareness of different interpretations is a crucial element of collective understanding in very diverse theories. In Piagetian terms (1970), cognitive models are taken to develop on the basis of consonance and dissonance with new information. Similar approaches underpin collective learning and decision-making models such as case-based reasoning (Aamodt 1997), where comparison of cases is the basis for discussion and learning. The representation and 
discussion of multiple perspectives is central to action research (Denzin, 1994) also, and stakeholder analysis (Beerel, 1998), as a means of highlighting a basic inconsistency (or incompatibility) that needs to be resolved, and thus informing, shaping or changing behaviour.

\subsection{Shared mental model 3: the organization}

Different conceptual relationships have salience for different groups of users, but the central configuring 'metaphor' for situating decision-making and action often seems to be the organization itself. (Figure 2). This provides both: -

(i) a conceptual frame or reference for collective understanding in context

(ii) a contextual frame of reference for decision-making and situated action

The ,problem: solution, patterns being shared tended to cluster at different layers that mirrored organisational structure.

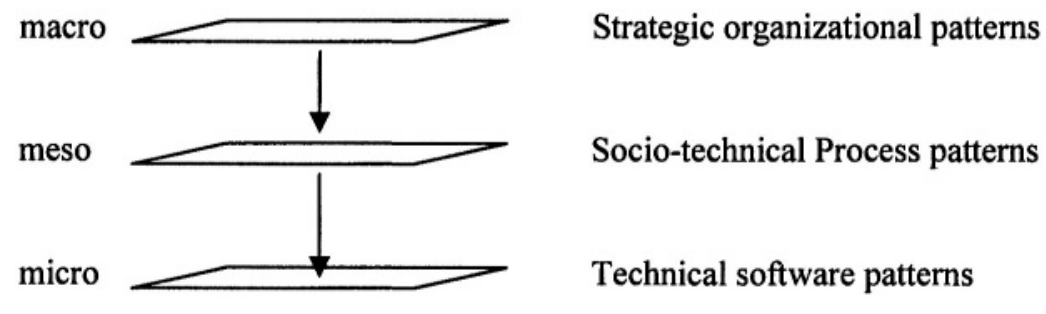

Fig.2 The organization as a unifying frame of reference

For example, knowledge of problem scenarios at a management level were very common, particularly where there were competing preferences for a design solution to a requirements problem. These were generic in many cases to other industries, and were associated with particular scenarios and possible solutions. They were 'socio-technical insofar as the related to the management of technology. At a process level, the problems were again often socio-technical, but related to knowledge of elegant solutions to the alignment of the technical and the human resource in ways which cut costs or added value or flexibility. (Lloyd et al, 2002; Ure and Jaegersberg, 2004). At the micro level, problems and solutions tended to be more technical than socio-technical and were more likely to be dealt with within the technology team rather than at inter-departmental workshops.

\section{DISCUSSION}

The paper highlights the use of different types of mental models as scaffolding for sharing distributed knowledge across domains. Clearly, models and assumptions can both facilitate and constrain the understanding of the problem, and the potential solutions. O'Connor et al (1997) points to the extent to which model-based 
assumptions and methods "create the world we later discover". In a sense, then, defining the problem scenario can constrain the solution as well as facilitate it.

Collective sense- making and effective decision-making is a mediated process at an individual and a collective level. Orlikowski, for example, refers to the 'lens' through which we see the world (Orlikowski, 1991). Our collective theoretical and decision-making models (tacit and explicit) often reinforce particular views to the exclusion of others, limiting the solutions that we can 'see'. Kuhn's (1966) work on the role of scientific 'paradigms' in sustaining particular worldviews highlights this, as Einstein also did by implication when he claimed that it is the theory that describes what we can observe.'

These (often tacit) frames of reference appeared to shape

(a) knowledge sharing and development in the first instance, with clusters of known problem: solution patterns organised in time, or in real or conceptual spaces

(b) situated decision-making, where the context provided an arena where the possible solutions could be evaluated or connected in the context of possible real world applications.

Both observation and interviews suggest that both knowledge transfer and decisionmaking was easier where an explicit or shared framework of this type was available, or could be created.

\subsection{Knowledge-building in heterogeneous and distributed communities}

One of the biggest challenges to the design and management of collaborative, networked systems, such as the supply chain, and grid-based web services, is the difficulty of sharing knowledge in a dynamic environment, across heterogeneous communities, (Brown, 1991; Lassila, 2001).

Clearly this 'social shaping' (Williams, 1997) of technological design may be constraining rather than enabling in some cases as the literature indicates. However it also suggests the importance of ensuring that the 'shared spaces' (Nonaka et al, 1998) that are an integral part of social networks are also explicitly built into the networks used by virtual teams in virtual environments. (Davis et al, 2000).

The pattern-building community of practitioners in this study leverages the potential of social networks to construct, the potential of technical networks to connect distributed communities (Davis, 2000), and the potential of patterns as a shared currency that can enable the process of representation, reflection, reconstruction or re-use.

Observation of the way in which the pattern language was created suggested that the collaborative process of pattern building provided a transient scaffolding mechanism for representing and aligning both knowledge and aims in the context of shared use, and also in the context of projected application. Interviews with users confirmed it as a particularly rich and focused basis for collaborative discussion, at both the generic level in terms of the configuration of the underlying forces, and at the more context specific level of application and use. The discussions and the resulting map of related patterns provided a basis for our perception of the role of 
shared mental models as a vehicle for both communication and construction. The resulting 'pattern languages' used as examples are connected in highly structured and very revealing ways -revealing in terms of: -

(a) the way distributed knowledge was structured or even constrained by a common organising framework

(b) the socio-technical nature of many of the most recurrent problems

\title{
3.2 Aligning aims as well as distributed knowledge
}

We note that the problems encapsulated in these patterns were not only associated with the difficulty of aligning knowledge across diverse domains. Many related to the difficulty of aligning competing aims, and were most evident at the decisionmaking stage. The criteria and aims of the design community, for example, were for a robust and elegant design with minimal delay and complication from emerging requirements, while the priority for the business community was to optimize their own ability to respond to changing business opportunities and requirements as they emerged, without being constrained by technical considerations. We hope to further explore this mechanism for the social 'shaping' of technology (Williams 1997, Orlikowski 1991, Walsham 2001).

\subsection{Socio-technical problems in the design of networked environments}

\author{
'Just in time (procurement systems) work in Germany. Why don,t they work in Parana. It's the same \\ technology, so what's the difference?' \\ Senior Technical Manager, Automotive Supply Chain
}

\begin{abstract}
Also noted was the evidence that 'People' related issues were often the recurring problems regarded as most likely to impact significantly on the competitiveness of the system. Interviews with senior managers in the automotive manufacturing supply chain, the oil and gas industry supply chain and the financial services industry underlined the cost of failing to map and manage socio-technical and socio-cultural problems in the extended enterprise (Ure et al 2004; Lloyd et al, 2002), and this is also a key finding in both current and previous research projects with system managers in industries as diverse a oil and gas, automotive manufacturing and product design.
\end{abstract}

\subsection{A ballpark and rules of play}

We suggest, as does Boisot, (1998), that knowledge transfer across heterogeneous groups requires identification or co-creation of a shared context within which knowledge makes sense or is to be implemented, if it is not already shared by the members of the community. Observation and interviews suggested the knowledge management workshops might have benefited as much from the provision of a shared space as from a particular process. They allowed stakeholders from different communities an opportunity to find shared frames of reference in which to situate an understanding of distributed knowledge, a shared lingua franca as a basis for 
constructing/reconstructing a shared view of the problem, and a context for negotiating situated actions.

Models can both facilitate or constrain perception of problems and potential solutions. In the case of distributed knowledge, fragmented across diverse domains of expertise, they are arguably an essential component of collective decisionmaking. If, as many commentators argue, the current problem is 'making sense' of the information generated by 'big' computing, in grid based systems, in agent based defense systems and in e-business systems, then there is a need for more focused research on the use of these mediating structures.

\section{ACKNOWLEDGEMENTS}

The authors would like to acknowledge the support of UK EPSRC Grant GR/M02491, and ESRC Grant L328253025).

\section{REFERENCES}

1. Aamodt, A. 1997. Experience-driven case-based reason. In Wess, S.; Althoff, K \& Richter, M. (ed.), Topics in CASE-Based Reasoning. Springer Verlag, 1994

2. Adams, J., Koushik S., Vasudeva G., and Galambos G. (2001), Patterns for e-business: A Strategy for Reuse, IBM Press

3. Alexander, C. 1964. A Synthesis of Form, Harvard University Press, Cambridge, Massachusetts.

4. Beerel A. 1998. Leadership Through Strategic Planning, Thomson Learning, Europe

5. Bijker, W.E., Hughes, T.P. and Pinch, T.F., (Eds), 1989 , The Social Construction of Technological Systems: New Directions in the Sociology and History of Technology, MIT Press, ISBN 0262521377

6. Boisot, M. 1998 Knowledge Assets: securing competitive advantage in the information economy. Oxford: Oxford University Press.

7. Brown J.S. \& Duguid P. 1991. Organizational learning and communities-of-practice, Organizational Science, (2)1: 40-57

8. Bush V. 'As We May Think', Atlantic Monthly, July, 1945

9. Checkland P. 1981. Systems thinking, systems practice. Chichester: Wiley.

10. Coplien, J.O. Schmidt, D.C. 1995. Pattern Languages of Program Design, Addison Wesley Publishing Company, ISBN: 0201607344.

11. Cranmore A., Ure J., Dewar R., Lloyd A., and Pooley R. 2002, Capacity Building in Enterprise Systems, EuroPLoP Conference

12. Davis M., Denning K., Watkins K and Milton J., 2000. Virtual Learning Communities: creating meaning through dialogue and enquiry in cyberspace, ALT-C 2000 Conference, Edinburgh.

13. Denzin, N. K., \& Lincoln, Y. S. 1994. Introduction: Entering the Field of Qualitative Research. In N. K. Denzin \& Y. S. Lincoln (Eds.), Handbook of Qualitative Research (pp. 1-17). Thousand Oaks: Sage.

14. Dewar, R.G., Lloyd, A. D., Pooley, R.J., Stevens, P. 1999. Identifying and communicating expertise in systems reengineering: a patterns approach. 1EE Proceedings-Software, 146(3): 145-152.

15. Gamma E,. Helm R., Johnson R., Vlissides J. 1995 Design Patterns : Elements of Reusable ObjectOriented Software, Addison-Wesley Professional Computing, ISBN: 0201633612.

16. Kolodner J. 1993. Case-based reasoning. San Mateo,CA. Morgan Kaufmann

17. Kuhn T.S. 1996. The Structure of Scientific revolutions, Univ. of Chaicago Proess. ( $3^{\text {rd }}$ Edition) ISBN: 0226458083

18. Lassila O. 1999. Resource Description Framework (RDF) Model and Syntax Specification. W3C recommendation http://www.w3.0rg/TR/1999/REC-rdf-syntax-19990222

19. Lloyd A.D., Dewar R. G., Pooley R.J. 1999. Legacy Information Systems and Business Process Change: A Patterns Perspective, CAIS, (http://cais.isworld.org/), vol.2, article 24. 
20. Lloyd A., Ure J., Cranmore A., Dewar R.G. and Pooley R.J. 2002. Designing Enterprise Systems: leveraging knowledge in a distributed pattern-building community, ISPE/CE Conference, Cranfield University. In Advances in Concurrent Engineering, Balkema Publishers/Swets and Zeitlinger, ISBN 9058095029

21. Nonaka, I. 1998. The concept of ,ba,: Building a foundation for knowledge creation. California Management Review, 40(3): 40-54.

22. O'Connor .J \& McDermott I. 1997. The Art of Systems Thinking, Thursons.

23. Orlikowski W. J. 1991 The Duality of Technology: Rethinking the Concept of technology in Organizations, Working Paper No 219, Center for Information Systems Research, MIT

24. Pooley R.J. and Stevens P. 1999. Using UML:Software Engineering with Objects and Components. Addison-Wesley.

25. Prusak, L. 1997 'Knowledge in Organisations', Butterworth Heinemann

26. Ross B.H. \& Kennedy P.T. 1990. Generalizing from the use of earlier examples in problem solving. Jouranl of Expertmental Psychology: Learning memory and Cognition, 16,42-55

27. Shneiderman B. 'Codex, Memex, Genex: The pursuit of transformational technologies' International Journal of Human-Computer Interaction 10,2 (1998c), 87-106.

28. Suchman L, 1987, 'Plans and Situated Actions: the problem with human machine communication.', Cambridge University Press. ISBN 0-521-33739-9

29. Tyre M. J. and Von Hippel, E. 1997. The situated nature of adaptive learning in Organizations, Organization Science, Vol. 8, No. 1, pp. 71-83.

30. Von KroghG.F. and Roos J. 1995. Organisational Epistemology'. London:Macmillan

31. Walsham G. 2001. Making a World of Difference: IT in a Global Context, Wiley.

32. Wenger E. 1998. Communities of Practice, Cambridge University Press.

33. Williams, R. 1997. The Social Shaping of a Failed Technology? Mismatch and Tension Between the Supply and Use of Computer-Aided Production Management. In Clausen, C. and Williams, R. (Eds.). The Social Shaping of Computer-Aided Manufacture and Computer-Integrated Manufacture, Luxembourg, COST A4. pp. 109-130. 